\title{
Effect of Lactic Acid Etching on Bonding Effectiveness of Orthodontic Bracket after Water Storage
}

\author{
Fahad F. Alsulaimani \\ Division of Orthodontics, Department of Preventive Dental Science, Faculty of Dentistry, King Abdulaziz University, \\ Jeddah, Saudi Arabia \\ Correspondence should be addressed to Fahad F. Alsulaimani; falsulaimani@kau.edu.sa
}

Received 19 November 2013; Accepted 16 January 2014; Published 17 March 2014

Academic Editors: A. Bardow, M. Del Fabbro, and P. Yaman

Copyright (C) 2014 Fahad F. Alsulaimani. This is an open access article distributed under the Creative Commons Attribution License, which permits unrestricted use, distribution, and reproduction in any medium, provided the original work is properly cited.

Objective. To determine the effect of lactic acid at various concentrations on the shear bond strength of orthodontic brackets bonded with the resin adhesive system before and after water storage. Materials and Methods. Hundred extracted human premolars were divided into 5 treatment groups and etched for 30 seconds with one of the following agents: lactic acid solution with (A) 10\%, (B) $20 \%$, (C) 30\%, and (D) 50\%; group E, 37\% phosphoric acid (control). Metal brackets were bonded using a Transbond XT. Bonding effectiveness was assessed by shear bond strength after 24 hours and 6 months of water storage at $37^{\circ} \mathrm{C}$. The data were analyzed with 2 -way analysis of variance and Tukey's Honestly Significant Difference (HSD) test $(\alpha=.001)$. Results. Lactic acid concentration and water storage resulted in significant differences for brackets bond strength $(P<.001) .20 \%$ lactic acid had significantly higher mean bond strength values (SD) for all conditions: 24 hours [12.2 (.7) MPa] and 6 months [10.1 (.6) MPa] of water storage. 37\% phosphoric acid had intermediate bond strength values for all conditions: 24 hours [8.2 (.6) MPa] and 6 months [6.2 (.6) MPa] of water storage. Also, there were differences in bond strength between storage time, with a reduction in values from 24 hours and 6 months for all experimental groups $(P<.001)$. Conclusion. Lactic acid could be used in place of phosphoric acid as an enamel etchant for bonding of orthodontic brackets.

\section{Introduction}

The efficacy of various agents as an enamel etchants during bonding of orthodontic brackets has been studied [1-11]. Nevertheless, phosphoric acid has remained the principal enamel etchant since it was first introduced by Buonocore [12] in 1955 and used by Newman [13] in 1965. Phosphoric acid concentration between $30 \%$ and $40 \%$ results in the most retentive etching pattern $[14,15]$.

Acid etching of enamel is recommended with many dentinal bonding systems to improve the delivery of orthodontic treatment [1]. Claims of comparable bond strengths to enamel and dentin with conventional methods of bonding have meant that these adhesives are also suitable for orthodontic bonding [15-19]. The development of an adhesive bond requires establishing intimate contact between the liquid adhesive and the solid adherent, minimizing the stress concentration at the interface and reducing the influence of environmental factors on the interface integrity [20-22].
Therefore, the materials which are used today to adhere to the hard tooth structure must resist the surrounding influences in the oral cavity, including temperature changes [23]. Moreover, the bond strength of adhesive and attachments should be sufficient to withstand all forces and stresses exerted by mastication and archwires. Although there is no formally accepted minimum clinical bond strength, 5 to $10 \mathrm{MPa}$ have been mentioned as being adequate for clinical situations [25].

Long-term stability of bonding to tooth structure remains questionable. A factor known to promote bond degradation is long-term water exposure $[6,7,24-26]$. Bond deterioration by water storage might be caused by degradation of interface components, such as denaturation of collagen and/or elution of degraded or insufficiently cured resin [23, 27]. Therefore, maintaining a sound unblemished enamel surface is a primary clinical concern when debonding the brackets after orthodontic treatment. Enamel fracture and cracks have been reported at the time of bracket debonding [28]. It is 
possible that the depth of the etched enamel surface created by phosphoric acid may be a contributing factor to the incidence of enamel fracture [29]. Therefore, to minimize the extent of enamel surface damage, alternative conditioners, such as maleic acid [30, 31], nitric acid [32], polyacrylic acid [33], and ethylenediaminetetraacetic acid [34], have been used to obtain clinically useful bond strengths by decreasing the depth of enamel dissolution.

Mount [35] suggested that etchants should be (1) isotonic to avoid osmotic pressure changes, (2) neutral pH or at least between $\mathrm{pH} 5.5$ and $\mathrm{pH}$ 8.0, (3) nontoxic to dentin, pulp, and gingival tissue, (4) compatible with the chemistry of the cementation agents, (5) water soluble and easily removed, (6) unable to deplete the enamel or dentin chemically, and (7) able to enhance the surface chemically in preparation for bonding. Although none of the currently available dentin etchants meet all these requirements, it would seem desirable to use a conditioning agent that had the least possibility of causing adverse reactions. Because lactic acid occurs naturally in the muscles under anaerobic conditions during muscular exercise, it is thought to be more biologically acceptable than other etchants $[36,37]$. However, its action as an alternative to phosphoric acid as enamel and dentin etchant has not been reported. The purpose of the present study was to determine the effect of lactic acid at various concentrations on the shear bond strength of orthodontic brackets bonded with Transbond XT resin adhesive at 24 hours and 6 months of water storage. The null hypothesis was that lactic acid etchant at different concentrations would have no influence on the shear bond strength of orthodontic brackets before and after water storage.

\section{Materials and Methods}

The study protocol was approved by the Institutional Research Board. The $\mathrm{pH}$ of the tested etching solutions was measured with a Corning $\mathrm{pH}$ meter (model 220, Corning Science Products, Corning, NY) equipped with Corning combination electrode. The $\mathrm{pH}$ reference solutions at $\mathrm{pH} 7$ and 4 were used to standardize the electrode. The average of three repeated measurements was determined.

Hundred intact recently extracted human upper premolars were debrided to remove remnants of periodontal ligaments and examined stereoscopically at $\times 10$ to verify the absence of cracks. The teeth were stored in distilled water with $0.1 \%$ thymol disinfectant (Mallinckrodt Baker Inc., Phillipsburg, NJ) at room temperature and used within 1 week after extraction. Crowns of the selected teeth were sectioned perpendicular to the long axis, $5 \pm 1 \mathrm{~mm}$ apical to the cementoenamel junction with a 0.15 diamond wafering blade (Buehler, Lake Bluff, IL) in an Isomet 1000 slow speed saw (Isomet, Buehler) under copious water cooling. Each crown was aligned horizontally in an individual polymeric tube (Buehler) and embedded in epoxy resin (Epoxide Resin, Leco Corp., St. Joseph, MI) so that the buccal surfaces projected well above the embedding material. A surveyor (J.M. Ney Co., Bloomfield, CT) was used to align the bonding surface perpendicular to the base of the mold. After complete polymerization, the specimens were polished to remove epoxy resin overflow. The buccal surfaces were cleaned with slurry of nonfluorinated pumice and water for 10 seconds, washed, and gently dried with an oil-free and moisture-free jet of air. Mounted teeth were stored in an atmosphere of $100 \%$ humidity.

The specimens were divided into 5 groups $(n=20$ per group) and etched with 1 of the following agents: lactic acid solution with (A) $10 \%$, (B) $20 \%$, (C) $30 \%$, and (D) $50 \%$ prepared at the Ohio State University, Department of Chemistry. The control group (E) was treated with $37 \%$ phosphoric acid (3 M Dental Products, Monrovia, CA). Etchant solutions were applied to enamel surfaces for 30 seconds with a cotton pledget and cotton pliers [14]. Immediately after etching, specimens were rinsed with water spray for 10 seconds in a direction that carried the acid away from the enamel surface. Transbond XT primer (3 M Unitek, Monrovia, CA) was applied on the etched enamel surfaces, and the metal maxillary premolar brackets (Mini-Taurus RMO, Denver, CO) were bonded onto the midbuccal surfaces using Transbond XT adhesive paste (3 M Unitek, Monrovia, CA) according to manufacturers' instructions. Transbond XT adhesive paste was applied to the base of the bracket which was then pressed firmly on to the tooth. Excess adhesive was removed from around the base of the bracket with a scaler and was light polymerized (UltraLume LED 5; Ultradent Products) for 10 seconds on each interproximal side at a $2 \mathrm{~mm}$ distance from each bracket face. Light intensity $\left(730 \mathrm{~mW} / \mathrm{cm}^{2}\right)$ was monitored by a radiometer (Demetron/Kerr, Danbury, CT) before every use. The bonded teeth were left undisturbed for 30 minutes to ensure complete polymerization of the adhesive material. All bonding procedures were performed by the same operator.

The failure loads for bonded brackets were determined on half of the specimens ( $n=10$ per group) after 24 hours, and the other half were stored in a hermetically sealed container with distilled water at $37^{\circ} \mathrm{C}$ to be tested after 6 months. Each specimen was locked in a special clamping device (Figure 1) mounted on the universal testing machine (Instron 4204; Instron Corp., Canton, MA). An occlusogingival load was applied to the area between the base and the wings of the bracket from a knife-edge fixture with a $1000 \mathrm{~N}$ load cell in the shear mode and a crosshead speed of $0.05 \mathrm{~mm} / \mathrm{min}$. The maximum loads were recorded and divided by the surface area of the bracket-enamel interface to obtain an estimate of the shear bond strength in megapascals ( $\mathrm{MPa})$.

An additional specimen from each group was treated and prepared for scanning electron microscopy (SEM) by mounting on aluminum stubs and sputter coating with very thin layer (approximately $1 \mathrm{~nm}$ ) of gold-palladium alloy (Cressingtons sputter coater, Cressington Scientific Instruments Ltd., Watford, United Kingdom), and it was observed by a single investigator with a scanning electron microscope (Philips Electron Optics, BV. Achseweg Noords, The Netherlands) at the center of each specimen. Raster scans were performed at $\times 3000$ magnification with an accelerating voltage of $15 \mathrm{KV}$. Mean values for each group were calculated, and differences between the groups were tested for statistical significance by use of 2-way analysis of variance and Tukey's Honestly Significant Difference (HSD) test $(\alpha=.001)$. 


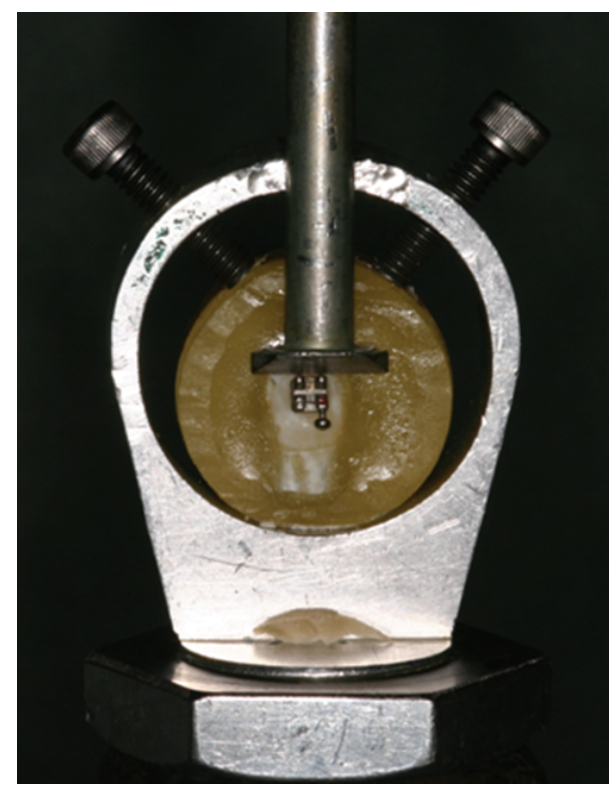

FIGURE 1: Special clamping device used in the study.

\section{Results}

The strength $(\mathrm{pKa})$ of the tested etching acids and their $\mathrm{pH}$ measurements are listed in Table 1 . The $\mathrm{pH}$ measurements for lactic acid were consistent and did not vary from the phosphoric acid.

One-way ANOVA for the results of shear bond strength revealed that there were significant differences between the group means $(P<.001)(\mathrm{df} 4, \mathrm{~F} 291.3, P<.001)$. Tukey's Honestly Significant Difference test disclosed a significant difference between each pair of surface treatments for each time of water storage.

The 2-way ANOVA results in Table 2 demonstrate a significant difference between the etchant $(P<.001)$ and the storage times $(P<.001)$. However, the interaction between etchant/storage time was not significantly different $(P=.65)$. Mean values and standard deviations for each treated group are listed in Table 3. The highest mean shear bond strength (SD) was obtained from the group treated with $20 \%$ lactic acid solution on the 24 hours [12.2 (.7) MPa] and 6 months [10.1 (.6) $\mathrm{MPa}]$ of water storage. This is about $49 \%$ and $63 \%$ more than $37 \%$ phosphoric acid etchant on the 24 hours $[8.2$ (.6) $\mathrm{MPa}]$ and 6 months $[6.2(.6) \mathrm{MPa}$ ] of water storage. $50 \%$ lactic acid etchant had the lowest shear bond strength on the 24 hours [5.1 (.5) $\mathrm{MPa}$ ] and 6 months [3.1 (.6) MPa] of water storage. This is about $61 \%$ and $100 \%$ less than $37 \%$ phosphoric acid etchant. There was a reduction in shear bond strength $(21 \%-65 \%)$ after 6 months of water storage for all groups $(P<.001)$.

Scanning electron microscopic (SEM) evaluation of the treated enamel surfaces of the specimens for 30 seconds revealed several types of morphological changes. The effect of $37 \%$ phosphoric acid illustrated in Figure 2(a), and the etching pattern obtained with $20 \%$ lactic acid is illustrated in
TABLE 1: Strength of acids and their $\mathrm{pHs}^{*}$.

\begin{tabular}{lcccc}
\hline Etchant & $\mathrm{pKa} 1$ & $\mathrm{pKa} 2$ & $\mathrm{pKa} 3$ & $\mathrm{pH}$ \\
\hline 37\% phosphoric acid & 2.12 & 7.21 & 12.67 & 0.16 \\
10\% lactic acid & 3.86 & - & - & 1.55 \\
20\% lactic acid & 3.86 & - & - & 1.40 \\
30\% lactic acid & 3.86 & - & - & 1.20 \\
50\% lactic acid & 3.86 & - & - & 1.07 \\
\hline${ }^{*}$ Power of hydrogen. & & & &
\end{tabular}

TABLE 2: Two-way repeated measure AVOVA.

\begin{tabular}{lcccc}
\hline Source of variation & $\mathrm{df}^{*}$ & $\mathrm{MS}^{* *}$ & F score & $P$ value \\
\hline Groups & 4 & 204.97 & 576.04 & $<.001$ \\
Time & 1 & 110.84 & 311.49 & $<.001$ \\
Group * time & 4 & .22 & .62 & .65 \\
Error & 90 & .36 & & \\
\hline
\end{tabular}

${ }^{*}$ Degree of freedom, ${ }^{* *}$ mean square.

TABLE 3: Shear bond strength (MPa) for experimental groups according to the type of etchant [mean $\left.\left(\mathrm{SD}^{*}\right) n=10\right]$.

\begin{tabular}{|c|c|c|}
\hline \multirow[b]{2}{*}{ Etchant } & \multicolumn{2}{|c|}{ Storage time } \\
\hline & $\begin{array}{c}24 \text { hours of } \\
\text { water storage }^{1}\end{array}$ & $\begin{array}{c}6 \text { months of } \\
\text { water storage }^{2}\end{array}$ \\
\hline $10 \%$ lactic acid ${ }^{\mathrm{a}}$ & $11.9(.6)^{\mathrm{f}}$ & $9.4(.7)^{\mathrm{g}}$ \\
\hline $20 \%$ lactic acid ${ }^{b}$ & $12.2(.7)^{\mathrm{h}}$ & $10.1(.6)^{\mathrm{i}}$ \\
\hline $30 \%$ lactic acid ${ }^{c}$ & $6.1(.6)^{j}$ & $4.1(.5)^{\mathrm{k}}$ \\
\hline $50 \%$ lactic acid ${ }^{\mathrm{d}}$ & $5.1(.5)^{1}$ & $3.1(.6)^{\mathrm{m}}$ \\
\hline $\begin{array}{l}37 \% \text { phosphoric } \\
\text { acid }^{\mathrm{e}}\end{array}$ & $8.2(.6)^{\mathrm{n}}$ & $6.2(.6)^{\mathrm{o}}$ \\
\hline
\end{tabular}

*SD: standard deviation.

Different superscript numbers represent significant differences between the shear bond strengths of each storage time $(P<.001)$. Different lowercase letters represent significant differences between the etchant $*$ storage times within each group $(P<.001)$.

Figure 2(b). SEM photomicrographs revealed it to be a welldefined apatitic-like crystal with intermittent interstices susceptible to resin penetration. Furthermore, etching increases the surface area and creates sites into which bonding agents can infiltrate and polymerize which results in adhesion.

\section{Discussion}

This study evaluated the effect of lactic acid surface treatment in different concentrations on shear bond strength of brackets bonded with the resin orthodontic adhesive system before and after water storage. The Transbond XT and metal brackets were employed in the current study due to their routine use at our dental school. Etch and bond technique using phosphoric acid is among those common bonding techniques used [2, $3,15,30,32]$. Premolars were used and the area of enamel surface used for bonding was similar to that used clinically when bonding orthodontic brackets. The bond strength of 


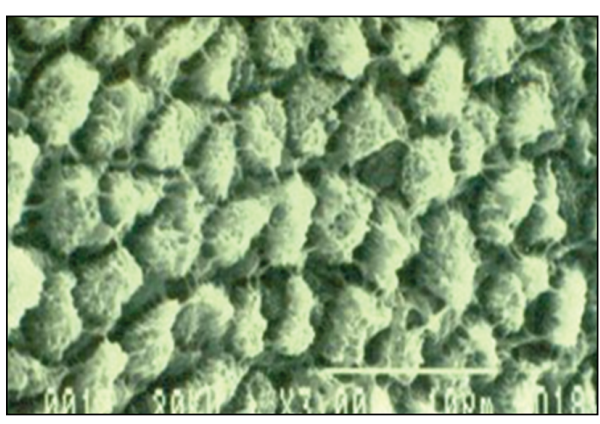

(a)

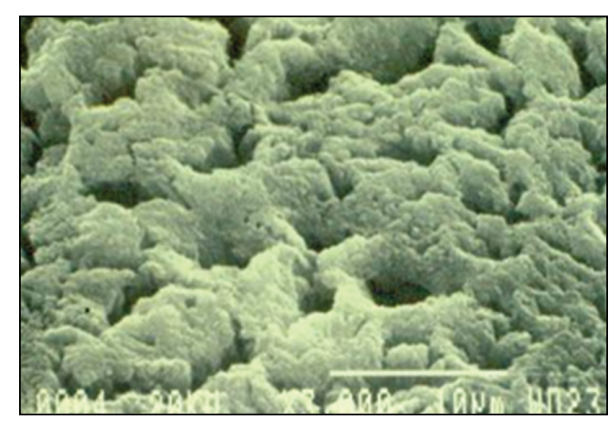

(b)

FIGURE 2: (a) SEM photomicrograph of enamel surface treated with 37\% phosphoric acid for 30 seconds. (b) SEM photomicrograph of enamel surface treated with $20 \%$ lactic acid for 30 seconds.

phosphoric acid etching has been shown to have clinically good values and the use of $5.25 \%$ sodium hypochlorite to eliminate the organic substances works together with it to increase the bond strength of the brackets-to-enamel surface [8].

Lactic acid etching is also among the techniques that have been suggested for treatment of enamel surface before being bonded [38]. The shear bond strength values of the current study were found to be near the clinically acceptable range recommended by Reynolds [5] who suggested a range of 5.9 to $7.8 \mathrm{MPa}$. The shear bond strength values of $6.1 \mathrm{MPa}$ and $5.1 \mathrm{MPa}$ presented with $30 \%$ and $50 \%$ lactic acid etchants for 24 hours of water storage and $4.1 \mathrm{MPa}$ and $3.1 \mathrm{MPa}$ for 6 months of water storage were statistically inferior to $37 \%$ phosphoric acid etchant (control) and were low in comparison with other researches [9-11]. However, the mean shear bond strength of $10 \%$ and $20 \%$ lactic acid was greater than the recommended values by Fritz et al. [17] to be adequate for routine clinical use.

Shinchi et al. [39] found that the adhesive strength of resin bonded to etched enamel depends mainly on the resin's ability to penetrate between the enamel crystallites and not necessarily to the depth of the enamel etched. In the current study, 20\% lactic acid roughened the enamel surface by selective dissolution of prism cores or peripheries, creating micropores into which resin could flow [40]. However, to achieve reliable bond, the possibilities involve interaction with hydroxyapatite or collagen. Because hydroxyapatite is present in both enamel and dentin, it would seem most logical that the material adheres to hydroxyapatite.

Though the test method used in the present study attempted to simulate the clinical situation, there were some limitations. Bond strength was performed shortly after bonding (24 hours) and after water storage (6 months) without any simulations of oral condition. However, clinically, the dislodgement of brackets commonly occurs after several years of function, and long-term retention may be influenced by various factors such as temperature changes and dynamic mechanical loading. Another limitation of this study was that the site of failure was not observed. Furthermore, the current study was a laboratory investigation and in vivo research must be carried out to confirm laboratory results.

\section{Conclusion}

Within the limitations of this study, the following conclusions can be drawn.

(1) Lactic acid etching could be used as an alternative to orthophosphoric acid etching when bonding orthodontic brackets with composite resin adhesive.

(2) Significant time differences were observed between $20 \%$ lactic acid bond strength and the $37 \%$ phosphoric acid (control) regardless of the storage time.

(3) Six months of water storage significantly reduced the shear bond strength regardless of the etchant used.

\section{Conflict of Interests}

The author declares that there is no conflict of interests regarding the publication of this paper.

\section{Acknowledgment}

This project was funded by the Deanship of Scientific Research (DSR), King Abdulaziz University, Jeddah, under Grant no. 211/165/1433. The author, therefore, acknowledges with thanks DSR technical and financial support.

\section{References}

[1] I. Amra, G. Samsodien, A. Shaikh, and R. Lalloo, "Xeno III selfetching adhesive in orthodontic bonding: the next generation," American Journal of Orthodontics and Dentofacial Orthopedics, vol. 131, no. 2, pp. 160.el1-160.e15, 2007.

[2] S. Keizer, C. J. M. Ten, and J. Arends, "Direct bonding of orthodontic brackets," American Journal of Orthodontics, vol. 69, no. 3, pp. 318-327, 1976.

[3] J. I. Lopez, "Retentive shear strengths of various bonding attachment bases," American Journal of Orthodontics, vol. 77, no. 6, pp. 669-678, 1980.

[4] F. Miura, K. Nakagawa, and E. Masuhara, "A new direct bonding system for plastic brackets," American Journal of Orthodontics and Dentofacial Orthopedics, vol. 59, pp. 350-361, 1971. 
[5] I. R. Reynolds, "A review of direct orthodontic bonding," British Journal of Orthodontics, vol. 2, pp. 171-178, 1985.

[6] W. N. Wang, C. L. Yeh, B. D. Fang, K. T. Sun, and M. G. Arvystas, "Effect of $\mathrm{H}_{3} \mathrm{PO}_{4}$ concentration on bond strength," Angle Orthodontist, vol. 64, no. 5, pp. 377-382, 1994.

[7] D. H. Sheen, W. N. Wang, and T. H. Tarng, "Bond strength of younger and older permanent teeth with various etching times," Angle Orthodontist, vol. 63, no. 3, pp. 225-230, 1993.

[8] R. Justus, T. Cubero, R. Ondarza, and F. Morales, "A new technique with sodium hypochlorite to increase bracket shear bond strength of fluoride-releasing resin-modified glass ionomer cements: comparing shear bond strength of two adhesive systems with enamel surface deproteinization before etching," Seminars in Orthodontics, vol. 16, no. 1, pp. 66-75, 2010.

[9] J. C. Dorminey, W. J. Dunn, and L. J. Taloumis, "Shear bond strength of orthodontic brackets bonded with a modified 1-step etchant-and-primer technique," American Journal of Orthodontics and Dentofacial Orthopedics, vol. 124, no. 4, pp. 410-413, 2003.

[10] T. Buyukyilmaz, S. Usumez, and A. I. Karaman, "Effect of selfetching primers on bond strength-are they reliable?" Angle Orthodontist, vol. 73, no. 1, pp. 64-70, 2003.

[11] T. N. Paskowsky, "Shear bond strength of a self-etching primer in the bonding of orthodontic brackets," American Journal of Orthodontics and Dentofacial Orthopedics, vol. 123, no. 1, p. 101, 2003.

[12] M. G. Buonocore, "A simple method of increasing the adhesion of acrylic filling materials to enamel surfaces," Journal of Dental Research, vol. 34, pp. 849-853, 1955.

[13] G. V. Newman, "Epoxy adhesives for orthodontic attachments: progress report," American Journal of Orthodontics, vol. 51, pp. 901-912, 1965.

[14] K. A. Galil and G. Z. Wright, "Acid etching patterns on buccal surfaces of permanent teeth," Pediatric Dentistry, vol. 1, no. 4, pp. 230-234, 1979.

[15] W. Carstensen, "The effects of different phosphoric acid concentrations on surface enamel," Angle Orthodontist, vol. 62, no. 1, pp. 51-58, 1992.

[16] M. Hannig, K. J. Reinhardt, and B. Bott, "Self-etching primer vs phosphoric acid: an alternative concept for composite-toenamel bonding," Operative Dentistry, vol. 24, no. 3, pp. 172-180, 1999.

[17] U. B. Fritz, P. Diedrich, and W. J. Finger, "Self-etching primersan alternative to the conventional acid etch technique?" Journal of Orofacial Orthopedics, vol. 62, no. 3, pp. 238-245, 2001.

[18] R. A. Miller, "Laboratory and clinical evaluation of a selfetching primer," Journal of Clinical Orthodontics, vol. 35, no. 1 , pp. 42-45, 2001.

[19] Y. Shimada, P. Senawongse, C. Harnirattisai, M. F. Burrow, Y. Nakaoki, and J. Tagami, "Bond strength of two adhesive systems to primary and permanent enamel," Operative Dentistry, vol. 27, no. 4, pp. 403-409, 2002.

[20] R. B. Ermis, J. de Munck, M. V. Cardoso et al., "Bond strength of self-etch adhesives to dentin prepared with three different diamond burs," Dental Materials, vol. 24, no. 7, pp. 978-985, 2008.

[21] J. W. van Dijken, "Durability of three simplified adhesive systems in Class V non-carious cervical dentin lesions," American Journal of Dentistry, vol. 17, no. 1, pp. 27-32, 2004.

[22] W. M. Al-Omari, C. A. Mitchell, and J. L. Cunningham, "Surface roughness and wettability of enamel and dentine surfaces prepared with different dental burs," Journal of Oral Rehabilitation, vol. 28, no. 7, pp. 645-650, 2001.

[23] E. A. M. Kidd, "Microleakage : a review," Journal of Dentistry, vol. 4, no. 5, pp. 199-206, 1976.

[24] H. Sano, T. Yoshikawa, P. N. Pereira et al., "Long-term durability of dentin bonds made with a self-etching primer, in vivo," Journal of Dental Research, vol. 78, no. 4, pp. 906-911, 1999.

[25] S. R. Armstrong, J. C. Keller, and D. B. Boyer, "The influence of water storage and $\mathrm{C}$-factor on the dentin-resin composite microtensile bond strength and debond pathway utilizing a filled and unfilled adhesive resin," Dental Materials, vol. 17, no. 3, pp. 268-276, 2001.

[26] A. J. Gwinnett and S. Yu, "Effect of long-term water storage on dentin bonding," American Journal of Dentistry, vol. 7, pp. 109111, 1994.

[27] J. P. Santerre, L. Shajii, and B. W. Leung, "Relation of dental composite formulations to their degradation and the release of hydrolyzed polymeric-resin-derived products," Critical Reviews in Oral Biology and Medicine, vol. 12, no. 2, pp. 136-151, 2001.

[28] J. C. Britton, P. McInnes, R. Weinberg, W. R. Ledoux, and D. H. Retief, "Shear bond strength of ceramic orthodontic brackets to enamel," American Journal of Orthodontics and Dentofacial Orthopedics, vol. 98, no. 4, pp. 348-353, 1990.

[29] S. Canay, I. Kocadereli, and E. Akca, "The effect of enamel air abrasion on the retention of bonded metallic orthodontic brackets," American Journal of Orthodontics and Dentofacial Orthopedics, vol. 117, no. 1, pp. 15-19, 2000.

[30] H. Urabe, P. E. Rossouw, K. C. Titley, and C. Yamin, “Combinations of etchants, composite resins, and bracket systems: an important choice in orthodontic bonding procedures," Angle Orthodontist, vol. 69, no. 3, pp. 267-274, 1999.

[31] W. W. Barkmeier and R. L. Erickson, "Shear bond strength of composite to enamel and dentin using Scotchbond MultiPurpose," American Journal of Dentistry, vol. 7, no. 3, pp. 175179, 1994.

[32] A. Gardner and R. Hobson, "Variations in acid-etch patterns with different acids and etch times," American Journal of Orthodontics and Dentofacial Orthopedics, vol. 120, no. 1, pp. 6467, 2001.

[33] R. Yamada, T. Hayakawa, and K. Kasai, "Effect of using self-etching primer for bonding orthodontic brackets," Angle Orthodontist, vol. 72, no. 6, pp. 558-564, 2002.

[34] Z. C. Çehreli and N. Altay, "Effects of a non-rinse conditioner and $17 \%$ ethylenediaminetetra acetic acid on the etch pattern of intact human permanent enamel," Angle Orthodontist, vol. 71, pp. 22-27, 2000.

[35] G. J. Mount, “Glass ionomer cements: clinical consideration," in Clinical Dentistry, J. W. Clark, Ed., Harper \& Row, Philadelphia, $\mathrm{Pa}, \mathrm{USA}, 1984$.

[36] D. Geoff, "Lactic acid is your friend," Bicycling, vol. 2, pp. 36-50, 1992.

[37] G. H. Bell, J. N. Davidson, and D. Enslie-Smith, Textbook of Physiology and Biochemistry, Elsevier, Saint Louis, Mo, USA, 1st edition, 1976.

[38] M. F. Ayad, S. F. Rosenstiel, and A. M. Farag, "A pilot study of lactic acid as an enamel and dentin conditioner for dentinbonding agent development," Journal of Prosthetic Dentistry, vol. 76, no. 3, pp. 254-259, 1996.

[39] M. J. Shinchi, K. Soma, and N. Nakabayashi, "The effect of phosphoric acid concentration on resin tag length and bond strength of a photo-cured resin to acid-etched enamel," Dental Materials, vol. 16, no. 5, pp. 324-329, 2000. 
[40] L. M. Silverstone, C. A. Saxton, I. L. Dogon, and O. Fejerskov, "Variation in the pattern of acid etching of human dental enamel examined by scanning electron microscopy," Caries Research, vol. 9, no. 5, pp. 373-387, 1975. 


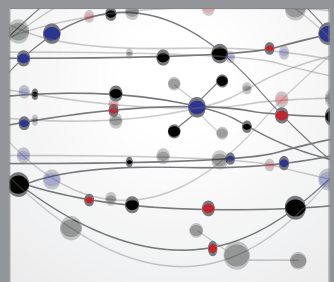

The Scientific World Journal
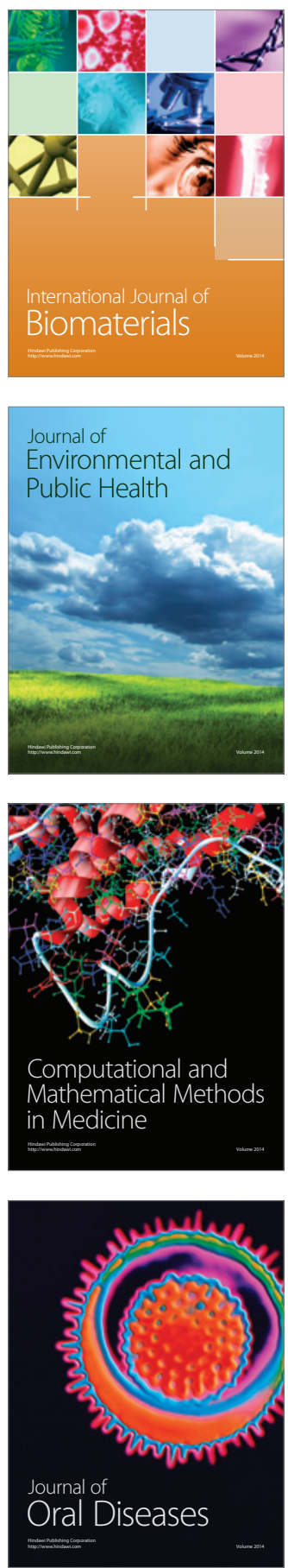
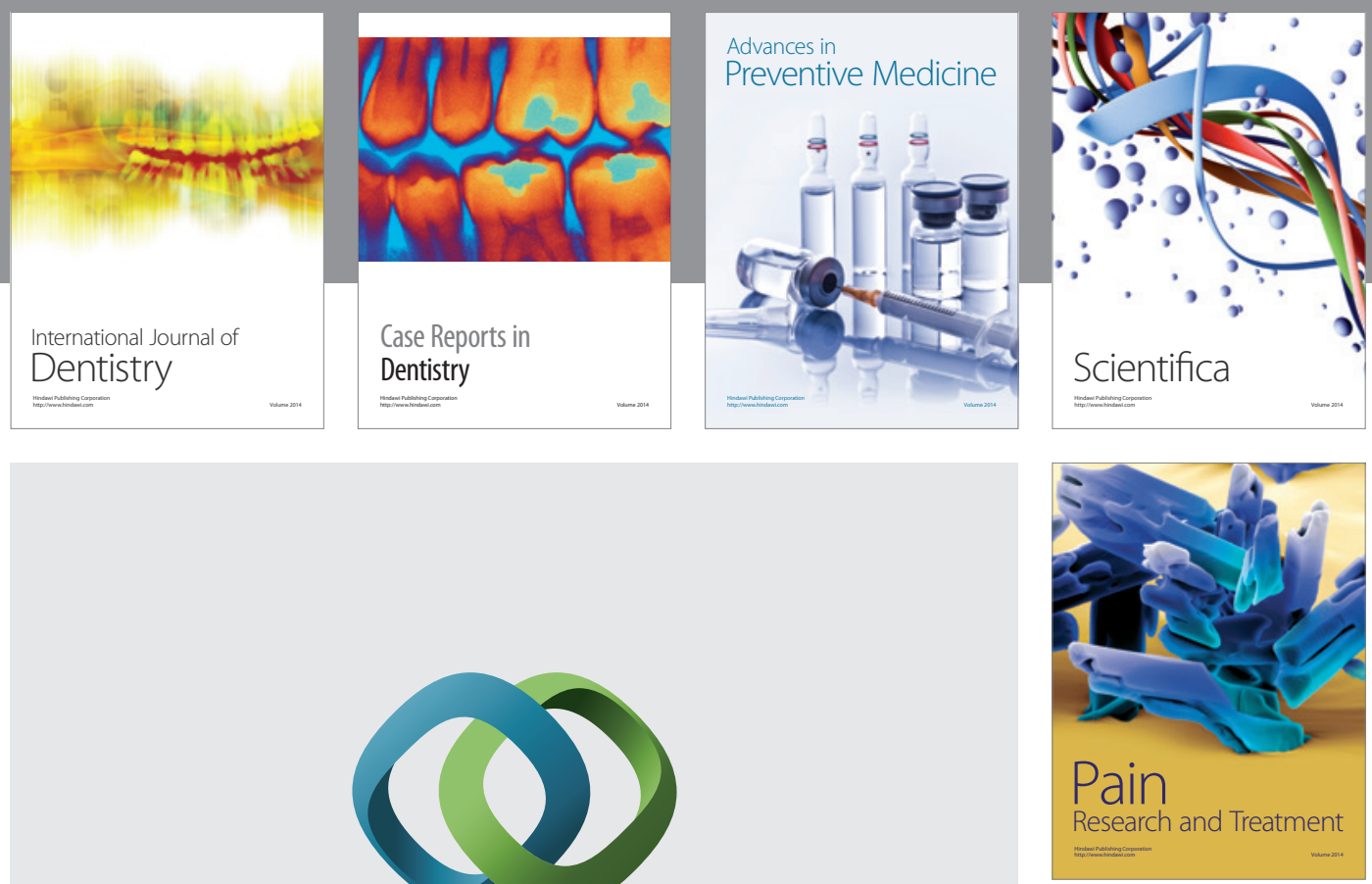

\section{Hindawi}

Submit your manuscripts at

http://www.hindawi.com
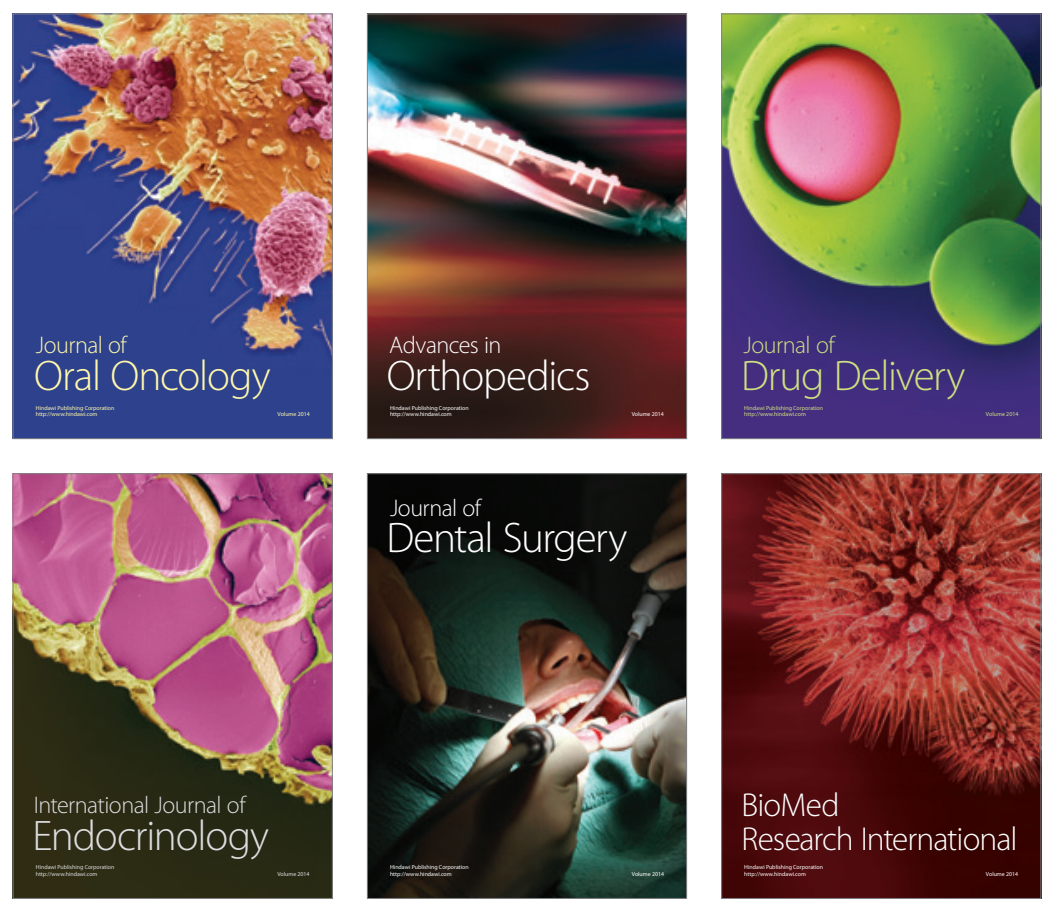

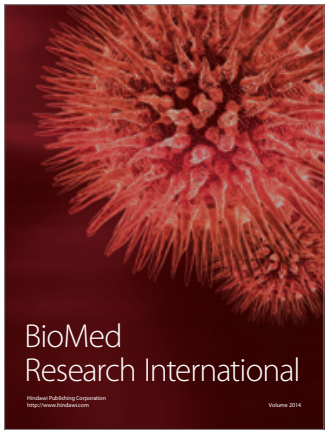

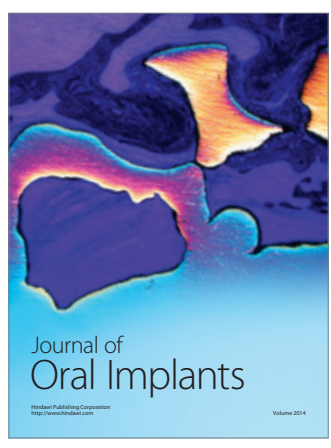
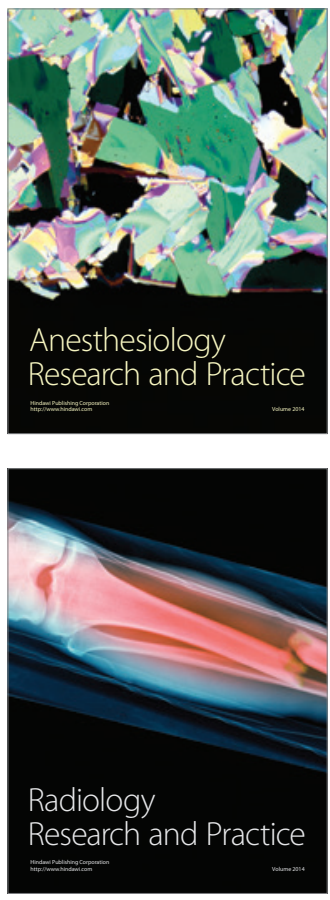